\title{
TAMIS repair of a rectal stenosis not treatable by endoscopy
}

\author{
J. Valdés-Hernández ${ }^{1}$ · F. J. Del Rio ${ }^{1}$ - J. C. Gómez-Rosado ${ }^{1}$ - J. Cintas-Catena ${ }^{1}$. C. Torres ${ }^{1}$ - A. Pérez-Sánchez ${ }^{1}$. \\ F. Oliva ${ }^{1} \cdot$ L. C. Capitán-Morales ${ }^{1}$
}

Received: 23 January 2018 / Accepted: 19 November 2018 / Published online: 26 November 2018

C) Springer Nature Switzerland AG 2018

Since the description of transanal endoscopic microsurgery (TEM) by Buess [1] and the later appraisal of transanal endoscopic operation(TEO) and tranasnal minimally invasive surgery (TAMIS) [2], these approaches have been used for the treatment of rectal neoplasms such as benign or early stage rectal cancer $[3,4]$.

Moreover, the transanal approach continues to evolve, and new indications are emerging, such as the removal of foreign bodies and repair of rectourethral fistula [4].

In this video, we present our experience with the TAMIS approach for the treatment of a rectal stenosis non-suitable for endoscopic dilatation.

A 48-year-old woman had a history of rectal stenosis and pelvic sepsis after transanal resection of a large polyp with high-grade dysplasia located in the mid rectum. Due to this process, a diverting colostomy was fashioned, drainage of the perirectal abscess was performed and a loose seton was placed.

After failure of conservative management, we decided to proceed with a TAMIS approach to the rectal stenosis. A proctoscopy and colonoscopy were done, and biopsies were also taken to rule out malignancy. The patient was prepared for surgery and informed consent was obtained.

A GelPOINT Path (Applied Medical) for rectal access was used. The stenosis was located around $6 \mathrm{~cm}$ from the anal verge.

A posterior rectotomy was carried out. Normal mucosa of the upper rectum was seen, and the presence of a rectal stenosis measuring $3-4 \mathrm{~cm}$ in length was confirmed.

Electronic supplementary material The online version of this article (https://doi.org/10.1007/s10151-018-1886-y) contains supplementary material, which is available to authorized users.

\section{J. Valdés-Hernández}

valdeshernandez@hotmail.com

1 Colorectal Surgery Unit, Virgen Macarena University

Hospital, Seville, Spain
The rectotomy was enlarged until the perirectal fat was seen and then a Foley catheter (18 F).

The patient was discharged uneventfully 1 day after the operation, and a proctoscopy with dilation was performed 1 month after surgery. The patient is now awaiting colostomy closure.

The TAMIS approach may be used as an alternative for the treatment of rectal stenosis in selected cases, if conservative treatment and endoscopic dilatation are not feasible.

\section{Compliance with ethical standards}

Conflict of interest The authors declare that they have no conflict of interest.

Ethical approval This article does not contain any studies with human participants performed by any of the authors.

Informed consent The patient was prepared for surgery and informed consent was obtained.

\section{References}

1. Buess G (1993) Transanal endocopic microsurgery (TEM). J R Surg Edinb 38:239-245

2. Atallah S, Albert M, Larach S. Transanal minimally invasive surgery: a giant leap forward. Surg Endosc 24:2200-2205

3. Albert M, Atallah S, deBeche-Adams T, Izfar S, Larach S (2013) Transanal Minimally Invasive Surgery (TAMIS) for local excision of benign neoplasms and early-stage rectal cancer: efficacy and outcomes in the first 50 patients. Dis Colon Rectum 56:301-3017

4. deBeche-Adams T, Hassan I, Haggerty S, Stefanidis D (2017) Transanal Minimally Invasive Surgery (TAMIS): a clinical spotlight review. Surg Endosc 31(10):3791-3800 